\title{
Reflexão de licenciandos em Biologia sobre a docência: uma experiência pautada pelo Enfoque CTS
}

Priscila Franco Binatto

Ana Cristina Santos Duarte

Paulo Marcelo Marini Teixeira

\section{Resumo}

O objetivo da pesquisa aqui relatada foi investigar processos reflexivos sobre docência desenvolvidos por licenciandos em Ciências Biológicas, em discussões e práticas realizadas no contexto da disciplina "Metodologia e Prática do Ensino de Biologia", orientadas pelos pressupostos do Enfoque CTS (Ciência Tecnologia e Sociedade). Para tanto, acompanhamos os estudantes na trajetória de atividades formativas proporcionadas pelo curso, por meio de um estudo qualitativo baseado em observação participante. Os registros de todo o processo foram fixados em um diário de campo e o tratamento dos dados foi orientado pela análise categorial temática, inspirada nos aportes da análise de conteúdo. Os resultados indicam contribuições para o entendimento da docência como prática social e política, que demanda reflexão e pesquisa contínua, além de despertar, nos participantes, o desejo de ser professor.

Palavras-chave: Enfoque CTS. Formação de Professores. Licenciatura. Reflexão. 


\title{
Reflection of Future Biology Teachers on Teaching from STS approach experiences
}

\author{
Priscila Franco Binatto \\ Ana Cristina Santos Duarte \\ Paulo Marcelo Marini Teixeira
}

\section{Abstract}

This work aim to investigate to investigate reflective processes on teaching developed by undergraduates in Biological Sciences, in discussions and practices conducted in the context of the discipline Methodology and Practice of Biology Teaching, guided by the assumptions of the STS (Science Technology and Society) approach. Therefore, we follow the students in the trajectory of formative activities provided by the course, through a qualitative study based on participant observation. The records of the whole process were fixed in a field diary and data analysis was guided by thematic categorical analysis, inspired by the content analysis inputs. The results indicate contributions to the understanding of teaching as a social and political practice, which demands reflection and continuous research, besides awakening, in the participants, the desire to be a teacher.

Keywords: STS Approach, Teachers qualification, Teacher Education Course. Reflection. 


\section{Introdução}

A Ciência e Tecnologia (C\&T), alvos constantes do fascínio humano, estão cada vez mais presentes em nossas vidas, de forma que fica difícil dissociá-las da sociedade moderna. Por outro lado, temas controversos como clonagem, transgênicos, reprodução assistida e energia, por exemplo, são alvos de dúvidas e preocupações por parte de estudantes e da população em geral. Questões como essas estão frequentemente presentes nas aulas, em especial de Biologia, sendo o papel dos professores contribuir para a construção de conhecimentos por parte dos alunos, estimulando discussões, reflexões, bem como, problematizando certos aspectos inerentes a essas temáticas.

Nessa perspectiva, o Movimento CTS, no contexto educacional, é um dos caminhos para atender essa demanda. De forma geral, os estudos CTS têm, desde a sua origem, nas décadas de 1960-70, um caráter político e social, tendo como objetivo a busca pela participação da sociedade nas políticas e atividades envolvendo C\&T, o desenvolvimento da capacidade de tomada de decisão, a aprendizagem de conceitos científicos, além da formação de valores aliados com o compromisso de construção de uma sociedade mais justa e igualitária (SANTOS, 2011; SANTOS, 2012; STRIEDER, 2008; TEIXEIRA, 2003).

Porém, de acordo com Fernandes e Strieder (2016), trabalhos sobre a compreensão das relações CTS entre professores, apontam para o desconhecimento e, consequente, escassez de práticas coerentes com esses pressupostos. Os professores do ensino médio, participantes da pesquisa conduzida pelas autoras supracitadas, declararam que a formação inicial e continuada é precária, no que se refere à compreensão e utilização dos pressupostos CTS no ensino e que, muitas vezes, os programas de formação docente continuam pautados por visões positivistas e ingênuas em relação à natureza da C\&T, tratando o conhecimento de forma fragmentada e estanque, dificultando a discussão dessas temáticas no contexto educacional. Outros autores trazem dados indicando as limitações das instâncias formativas em contribuir para que os professores de Ciências superem visões ingênuas de C\&T e favoreçam a responsabilidade social dos docentes no compromisso de construção da cidadania (AZEVEDO et al., 2013; BISPO FILHO et al., 2013; CHAPANI, 2010; FERRAZ, 2009).

Também em relação à C\&T, é preciso compreender que elas podem servir muito mais aos interesses econômicos e políticos ligados às classes dominantes do que ao bem-estar coletivo. Nesse sentido, é importante considerar que, dependendo da forma como o processo for conduzido, os pressupostos do Movimento CTS podem ser utilizados na formação de professores, a partir de uma perspectiva técnica, o que limitaria a criação de espaços para o desenvolvimento crítico dos docentes. 
Muitos trabalhos apresentaram e/ou investigaram propostas embasadas nos pressupostos do Enfoque CTS $^{19}$ como possibilidade formativa para futuros professores da área de Ciências Naturais, o que indica um caminho de possibilidades (BINATTO, 2015; CARNIO, CARVALHO, 2013; SOARES, 2012; ROZA, 2011; HUNSCHE, 2010; MARTÍNEZ, 2010; CASSIANI, LINSINGER, 2009; MION, ALVEZ, CARVALHO, 2009; PEDRETTI et al., 2006; DASS, 2005).

Assim, ao mesmo passo que crescem as pesquisas sobre formação de professores, aumenta a multiplicidade de entendimentos sobre esse campo, o que pode gerar dúvidas, controversas e conflitos que dificultam os avanços no que se refere às práticas e transformações de programas de formação de professores. A multiplicidade de sentidos nos direciona para a necessidade de explicitar a natureza, os objetivos e lógicas que permeiam a concepção formativa, considerando o espaço, tempo e contexto em que se situam.

Desta forma, pretendíamos com a pesquisa responder a seguinte questão problema: quais as possíveis contribuições da inserção dos enfoques CTS para processos reflexivos na formação de professores?

Para tanto, buscamos suporte nos referenciais sobre o papel da formação reflexiva, em especial nas ideias propostas por Zeichner (1993), a fim de atender o objetivo de investigar as reflexões sobre a docência realizadas pelos alunos em discussões e práticas desenvolvidas segundo os pressupostos defendidos pelo Movimento CTS.

\section{A reflexão na formação docente}

A origem do termo reflexão (reflexivo) é relacionada principalmente aos trabalhos de John Dewey, em especial, ao seu livro “How we think”, publicado em 1933 (ZEICHNER, 1993). De acordo o referido autor a ação reflexiva é definida como "uma consideração ativa, persistente e cuidadosa daquilo que se acredita ou que se pratica à luz dos motivos que o justificam e das consequências a que conduz" (p. 18). Essa se diferencia do ato de rotina, que é principalmente orientado pela tradição, impulso e autoridade. $\mathrm{O}$ ato de rotina reforça as ideologias e práticas dominantes, impedindo os professores de realizar grandes rupturas e experimentar opiniões alternativas.

Segundo Zeichner (1993), o ensino reflexivo é aquele que orienta a atenção dos futuros professores a ultrapassar o contexto da própria prática e voltar-se também para o desenvolvimento dos estudantes, para o reconhecimento das condições em que essas práticas

${ }^{19}$ Alguns dos autores citados utilizam a expressão CTSA, com objetivo de evidenciar as problemáticas ambientais decorrentes do desenvolvimento científico e tecnológico. Em nosso entendimento, as questões ambientais estiveram (e estão) presentes no Movimento CTS desde a sua origem. Assim, não julgamos ser necessária a inclusão da letra A na sigla, mas sim a explicitação dos objetivos vinculados a cadaabordagem CTS. Desta forma, optamos por manter a expressão CTS, ainda que o autor citado tivesse adotado CTSA. 
se situam, considerando dimensões políticas, culturais, e especialmente as sociais. Nessa perspectiva, a reflexão é prática social coletiva e contínua, em que os professores devem assumir as decisões sobre o ensino e avaliar as ações em sala de aula visando contribuir para a igualdade e para uma sociedade mais justa.

Zeichner (1993) apresenta cinco tradições históricas sobre as práticas reflexivas no ensino: i) a acadêmica: preocupada com os conteúdos específicos e a tradução desses para os alunos; ii) a de eficiência social: objetiva a aplicação de estratégias de ensino planejadas e sugeridas por especialistas; iii) a desenvolvimentista: prioriza o ensino centrado no aluno e nos seus interesses e padrões de desenvolvimento; $i v$ ) a de reconstrução social: destina atenção ao contexto social e político no intuito de contribuir com a construção de uma sociedade justa; e, por fim, a v) genérica: que não se aprofunda nos sentidos da reflexão, considerando que o ensino é necessariamente melhor quando os professores refletem sobre suas práticas.

Considerando a diversidade de tradições apontadas, Zeichner (1993) defende a importância de se especificar o conteúdo e a qualidade da reflexão, no que se refere aos processos de formação de professores, para que essa possa contribuir com a preparação para o ensino em condições variadas, tanto sociais como culturais. Sendo assim, o conceito de professor reflexivo articula-se às ideias propostas pelo Enfoque CTS crítico para o ensino de Ciências, conforme apresentado por Binatto, Chapani e Duarte (2015).

\section{O Enfoque CTS no ensino de Ciências}

O Enfoque CTS na educação pode ser entendido como perspectiva que pretende favorecer a interseção de propósitos entre o ensino de Ciências, a educação tecnológica e a formação para a cidadania, em que os conteúdos científicos e tecnológicos são discutidos em abordagem integrada com seus aspectos históricos e sociocientíficos (SANTOS, 2012).

De acordo com Martínez (2010) as características do contexto latino-americano favorecem a emergência de abordagens CTS críticas, que comungam a preocupação com a formação cidadã, incorporando discussões sobre as implicações sociais, políticas e ambientais da C\&T. Martínez (2010; 2012) apresenta o Enfoque CTS em quatro fases: origem, desenvolvimento, consolidação e ampliação. A origem, entre as décadas de 1960 e 1970, é marcada pelo questionamento ao ensino de Ciências centrado na apropriação mecânica de conteúdos científicos e na formação voltada para a preparação de técnicos e cientistas para atender as demandas específicas geradas pelo sistema capitalista. Na fase de desenvolvimento, entre as décadas de 1970 a 1980, evidencia-se a preocupação dos professores e pesquisadores de diversos países em consolidar um movimento de renovação curricular. Como resposta a essas preocupações, a década de 1990, período da consolidação, contava com propostas de currículos com Enfoque CTS. Enquanto alguns currículos seguiam uma tendência técnica, 
sendo produzidos por especialistas, outros eram construídos com a participação dos professores. Na fase de ampliação, correspondente ao momento atual, na qual temos observado movimentos de recontextualização do Enfoque CTS, que trazem intencionalidades semelhantes, como por exemplo, as "questões sociocientíficas" (QSC).

No Enfoque CTS o professor assume o papel de mediador das situações de aprendizagem, buscando criar condições para que os alunos possam se envolver de forma ativa nas discussões, articular conceitos, favorecer a argumentação e analisar criticamente o conhecimento científico, considerando o caráter político presente nessa abordagem (MARTÍNEZ; LOZANO, 2013; PINHEIRO; SILVEIRA; BAZZO, 2007; TEIXEIRA, 2003; BAZZO; VON LINSINGER; PEREIRA, 2003).

De acordo com Martínez e Lozano (2013), a partir do Enfoque CTS, o professor não se limita ao domínio de conhecimentos disciplinares, o que requer compreensão ampla dos aspectos filosóficos, éticos, morais e políticos da C\&T. A abordagem em sala de aula, segundo os referidos autores, demanda ainda abertura para a discussão de aspectos controversos e condições para análise das contribuições e limites das atividades científicas e tecnológicas na sociedade.

Dessa forma, é importante que os programas de formação docente, oportunizem a discussão das concepções de C\&T trazidas pelos docentes ou futuros docentes, a fim de que compreendam essas atividades como construções humanas, elaboradas por sujeitos em interação, sendo, portanto, sujeitas às influências sociais, econômicas e políticas. Também é importante favorecer a compreensão da capacidade intelectual inerente à docência, considerando tanto a importância dos futuros professores se apropriarem - de forma crítica das investigações já realizadas sobre o ensino, como reconhecendo a capacidade dos mesmos para desenvolver suas próprias investigações (ZEICHNER, 1993). Esse empoderamento dos professores também favorece a compreensão da importância da participação deles na organização do trabalho nas escolas. Entendendo que a prática docente sofre influência de determinantes sociais que são reflexos das contradições da sociedade (GHEDIN, 2004), podese buscar problematizar o ensino a fim de favorecer a formação crítica dos estudantes.

\section{Metodologia}

O presente trabalho é um recorte da pesquisa de mestrado que analisou discussões coletivas realizadas na disciplina Metodologia e Prática no Ensino de Biologia, tendo 10 alunos como participantes. A disciplina faz parte do elenco de atividades que compõe o currículo da Licenciatura em Ciências Biológicas da UESB/Jequié-BA e previa a realização integrada de três atividades básicas, considerando a formação do futuro professor: o ensino, a extensão e a pesquisa. Essas atividades aconteciam, respectivamente, no estágio de regência, na realização de minicursos destinados aos estudantes da educação básica, e na elaboração do 
trabalho de conclusão de curso (TCC). Porém, para fins deste trabalho, consideraremos apenas os dados relativos à regência e aos minicursos desenvolvidos.

A escolha da disciplina, como contexto para a realização da pesquisa, se justificou no fato de ter sido estruturada com base nos referenciais do Movimento CTS e nas proposições de Giroux (1997), no que se refere à ideia de professor intelectual transformador. Assim, o professor responsável pela referida disciplina, buscou articular tais referenciais aliando teoria e prática na proposta do estágio supervisionado.

Trata-se de uma pesquisa de caráter qualitativo, focando atenção em situações contextuais, atribuindo-se maior relevância ao processo em relação ao produto, cujos dados coletados seguem caráter descritivo e a análise segue um caráter indutivo (BOGDAN; BIKLEN, 1997). Para a obtenção de dados, optamos pela observação participante que, para Jorgensen (1989), é a metodologia indicada para estudar processos envolvendo a interação entre pessoas em situações e contextos particulares, favorecendo a abordagem qualitativa. Os dados foram obtidos também pela aplicação de um questionário para a identificação do perfil dos estudantes e suas percepções iniciais sobre a docência, bem como ao longo do desenvolvimento da disciplina, em especial nos momentos de estudo, planejamento, implementação e avaliação coletiva da regência e minicursos que os futuros professores desenvolveram no ensino médio, orientados pela perspectiva do Enfoque CTS no ensino de Biologia. Como forma de registro de dados, adotamos as gravações em áudio de todas as aulas, bem como notas de observação registradas em memorial descritivo. Além da observação participante, também obtivemos os dados pela transcrição das aulas gravadas (30 horas de gravação), pelas atividades solicitadas na disciplina, recolha de planos de aula (regência e minicursos) e das narrativas reflexivas produzidas pelos alunos.

As gravações foram transcritas e analisadas de acordo com as orientações de Bardin (2011) para a análise de conteúdo. Para apresentação das categorias analíticas realizamos uma descrição selecionando aspectos que se fizeram relevantes na análise dos dados e que tinham significado para o nosso objetivo de pesquisa. Esses aspectos foram interpretados à luz das teorias que embasaram nossas análises e exemplificados a partir de alguns trechos extraídos dos diferentes instrumentos utilizados na pesquisa.

Ao longo do texto, as citações referentes a depoimentos dos participantes da pesquisa que foram extraídas das transcrições de gravações das aulas, serão referidas com o termo aluno, seguido de uma letra do alfabeto (Exemplos: Aluno A, Aluna B, Aluno C, ...). Já as oriundas das atividades realizadas pelos licenciandos, farão relação direta à atividade, como por exemplo: Trecho da narrativa do Aluno A, Trecho retirado das Fichas Reflexivas do grupo de Energias Alternativas. 
Como recorte para os fins desse artigo, consideramos apenas as reflexões relacionadas à docência emergentes nas discussões realizadas pelos futuros professores sobre o estágio de Biologia - Ensino Médio.

\section{Resultados e discussão}

A partir do processo de análise dos dados emergiram seis categorias para organizar o conteúdo das reflexões dos licenciandos expostas sinteticamente no quadro abaixo:

Quadro 01: Descrição das categorias que emergiram das análises desenvolvidas.

\begin{tabular}{|c|c|}
\hline Categoria & Descrição \\
\hline $\begin{array}{l}\text { Reconhecimento r da } \\
\text { docência como prática } \\
\text { social }\end{array}$ & $\begin{array}{l}\text { Compreensão de docência manifestada pelos licenciandos durante } \\
\text { a disciplina, em especial, nos momentos de reflexão sobre a prática, } \\
\text { promovidos nos últimos encontros da disciplina. }\end{array}$ \\
\hline $\begin{array}{l}\text { A responsabilidade social } \\
\text { dos professores }\end{array}$ & $\begin{array}{l}\text { Evidencia o papel do professor em oportunizar igualdade de } \\
\text { condições para que todos os alunos possam aprender. }\end{array}$ \\
\hline $\begin{array}{l}\text { A relevância da pesquisa e } \\
\text { reflexão sobre a prática: } \\
\text { caminhos para } \\
\text { emancipação docente }\end{array}$ & $\begin{array}{l}\text { Aborda os entendimentos dos licenciandos sobre o papel da } \\
\text { pesquisa e dos processos reflexivos sobre a prática docente; e alguns } \\
\text { aspectos que caracterizamos como aproximações de uma busca pela } \\
\text { emancipação (noções de autonomia, importância da teoria e crítica } \\
\text { à ideia do professor como técnico). }\end{array}$ \\
\hline $\begin{array}{l}\text { Autorreflexão } \begin{array}{l}\text { sobre } \\
\text { prática }\end{array} \\
\text { reconhecimento docente: } \\
\text { próprias limitações }\end{array}$ & $\begin{array}{l}\text { Expressão de uma prática autorrefletida, em que o professor busca } \\
\text { rever e examinar suas ações no intuito aprimorá-las. }\end{array}$ \\
\hline $\begin{array}{l}\text { Autoformação contínua: em } \\
\text { busca da superação dos } \\
\text { limites da formação inicial }\end{array}$ & $\begin{array}{l}\text { Aborda o reconhecimento, por parte dos licenciandos, de que o } \\
\text { processo de aprender a ensinar não se encerra na formação inicial, } \\
\text { mas se prolonga por toda a carreira, na busca contínua do } \\
\text { aprimoramento de sua prática. }\end{array}$ \\
\hline $\begin{array}{l}\text { O processo } r \\
\text { fortalecimento de } \\
\text { pela docência. }\end{array}$ & $\begin{array}{l}\text { A proposta de formação, embasada pelos referenciais do Enfoque } \\
\text { CTS em perspectiva crítica, contribuiu para fortalecer o desejo de } \\
\text { ser professor. }\end{array}$ \\
\hline
\end{tabular}

Fonte: Elaboração dos autores.

\section{Reconhecimento da docência como prática social}

De acordo com Zeichner (1993), a reflexão pode contribuir com o desenvolvimento dos professores, quando assume o caráter de um compromisso enquanto prática social, em que, por meio de comunidades de aprendizagem, os professores "apoiam e sustentam o crescimento uns dos outros" (p. 26). O referido autor considera que tal característica assume valor estratégico, por possibilitar aos professores a revisão coletiva das condições de seu trabalho, visando mudança institucional e social.

O reconhecimento da docência como prática social coletiva se manifestou nos participantes da pesquisa, isto é, nos licenciandos participantes da referida disciplina, tanto pela valorização da importância do aprender com o outro, do trabalho em equipe, do planejamento e desenvolvimento de ações coletivas, como no compartilhamento das 
dificuldades que ocorreram ao longo do curso. Segundo os participantes, os professores devem ter como objetivo coletivo a aprendizagem dos alunos.

Outra evidência da compreensão, por parte dos licenciandos, da docência como prática coletiva se manifestou na percepção de que muitos dos problemas que vivenciam são compartilhados pelo coletivo de professores e envolvem a estrutura da escola e dos sistemas educativos. Segundo Zeichner (1993), a reflexão, quando incentivada de maneira individualizada, não permite essa compreensão por parte dos docentes e desfavorece "uma análise crítica das escolas enquanto instituições para uma preocupação com seus fracassos individuais” (p. 23). Os relatos abaixo citados exemplificam as percepções de docência como prática coletiva manifestadas entre os licenciandos:

"Essa oportunidade de estar junto com mais dois colegas, assumindo a profissão de professor, contribuiu bastante, porque a gente pôde perceber nas ações do outro e tentar melhorar a nossa atuação. [...]” (Aluna J);

“[...] nos preparativos para a regência com a elaboração e reelaboração de meu plano de aula para uma turma de segundo ano do ensino médio, pude sair da mesmice e dar ouvidos às diversas vozes de colegas docentes, experientes e ainda por se formar, que puderam enriquecer grandemente a minha experiência no estágio [...] Nesse sentido, perceber que não estava só em muitas das minhas angústias e dificuldades foi reanimador." (Trecho da narrativa do Aluno A);

"Também perceber que as dificuldades que cada um enfrenta na "sua" sala de aula, na realidade é um problema comum a todo educador, visto que na sala ao lado acabam passando por dificuldades e aflições parecidas.” (Aluno C)

Os licenciandos demonstraram ainda reconhecer o caráter político da docência, entendendo por um lado, a impossibilidade de assumir um papel de neutralidade e, por outro, a responsabilidade dos professores no sentido de buscar, em suas práticas, ações que possam minimizar questões de desigualdade e injustiça que permeiam a sala de aula. De acordo com Giroux (1997), as escolas são locais de disputa de poder e controle social, sendo importante que os professores reconheçam e repensem os interesses políticos e ideológicos, relações sociais e valores que guiam suas atividades de ensino, o que pressupõe assumir uma postura política. Vejamos abaixo parte dos relatos dos alunos que parecem se amparar nessa perspectiva:

“[...] o professor, o pessoal também é político, e o pessoal dentro da sala de aula do professor, pode ser muito bom, mas também pode ser muito ruim dependendo da maneira que ele se posiciona [...].” (Aluna F);

"A partir do estudo da Disciplina em questão e, sobretudo através da experiência do estágio, foi possível repensar no trabalho do professor, nas responsabilidades inerentes a essa profissão, que vão além da aplicação de conteúdos. É crucial que o docente tenha clareza da dimensão política de sua prática, e que a educação está a serviço de uma ideologia dominante. [...] não há como assumir uma prática docente pautada na neutralidade, pois essa postura consiste em reproduzir, manter a sociedade historicamente constituída" (Trecho da Narrativa do Aluno C). 
Esse entendimento dos licenciandos se aproximou do que discute Zeichner (1993, 2002, 2008), ao considerar a tendência democrática e emancipatória que envolve a prática reflexiva, atribuindo uma grande importância às decisões dos professores relacionadas à justiça social.

O desenvolvimento da percepção da docência como prática social e, portanto, prátoca política, é bastante relevante se consideramos os referenciais do ensino de Ciências a partir de um Enfoque CTS crítico. A nosso ver, a prática coletiva pode favorecer a abordagem interdisciplinar de temas e a aproximação entre Ciências Exatas e Humanas. Já a percepção do caráter político da docência leva os professores a examinar suas crenças e buscar, por meio de suas ações, desvelarem os mitos que permeiam C\&T a serviço de uma ideologia dominante.

\section{A responsabilidade social dos professores}

Segundo Zeichner (1993), a formação docente deve ajudar os futuros professores a desenvolverem uma responsabilidade social em sua profissão, para que atuem em busca de reduzir os efeitos nocivos das desigualdades que atravessam as nossas escolas, nossos estudantes e a sociedade como um todo.

Aliada à já relatada percepção de que a docência tem caráter político, manifestou-se nos licenciandos, a compreensão de que é papel do professor oportunizar igualdade de condições para que todos os alunos possam aprender. Assim, os participantes da pesquisa acreditam que é importante considerar o contexto social dos alunos e defendem o comprometimento dos professores com o ensino e no cuidado com o planejamento de suas aulas. Os trechos abaixo apresentados trazem depoimentos dos alunos neste sentido:

“[...] não precisa de a gente fichar [rotular], ah é um colégio periférico, eles estudam a noite, a gente não forçar, não vai passar conteúdo, a gente passa se quiser, o ano já está corrido [...]. Talvez a gente pensa em preparar a aula do noturno diferente do matutino porque os alunos são diferentes. São diferentes, mas em riqueza de conteúdo, de conhecimento, de temas a ser tratado [...]". (Aluno A);

"Você não pode limitar o aluno. [...]. Você tem que proporcionar condições iguais para todos." (Aluno C);

"[...] o turno noturno, com a carga de trabalho exaustiva de alguns alunos, que trabalham, que têm filhos já. Eu não achei isso empecilho para o ensino de Biologia. O maior empecilho está na nossa casa, quando a gente está preparando a aula. Essa foi a maior dificuldade que eu encontrei." (Aluno A).

Em consonância com o entendimento da função social do ensino de Biologia e coerente com a responsabilidade social dos professores, os participantes apontam como um dos caminhos para atingir este objetivo, o desenvolvimento da formação crítica de seus alunos, sendo o papel dos professores ajudar os estudantes no desvelamento de ideologias que, 
dificilmente perceberiam sem o auxílio docente, conforme é possível identificar nos trechos abaixo:

"o aluno não vai conseguir fazer isso [reconhecer o caráter político da Biologia] sozinho, ele não vai ser autodidata nesse sentido, o professor tem a responsabilidade de mostrar para o aluno o quão significativo aquilo é." (Aluno A).

"[...] o professor precisa estar apto a todos os assuntos envolvendo o social, político, econômico. Neste sentido é cada vez mais importante contribuir para a formação de cidadãos livres, responsáveis e críticos para participarem ativamente na vida em sociedade, para que consigam acompanhar o desenvolvimento científico-tecnológico" (Trecho da Narrativa Aluna I).

Como se nota, os participantes da pesquisa demonstram a percepção de que o conhecimento sistematizado é importante para embasar e favorecer a participação social e atuação política, objetivos frequentemente presentes nas discussões embasadas pelo Enfoque CTS (SANTOS, 2011; SANTOS, 2012; STRIEDER, 2008; TEIXEIRA, 2003). Portanto, demonstraram se aproximar da compreensão sobre a responsabilidade dos professores na mediação entre a análise crítica do conhecimento científico, bem como o uso desse conhecimento em situações cotidianas e aspectos de tomada de decisão e participação política, tal como defendem diversos autores da área (MARTÍNEZ; LOZANO, 2013; PINHEIRO; SILVEIRA; BAZZO, 2007; TEIXEIRA, 2003; BAZZO; VON LINSINGER; PEREIRA, 2003).

É importante considerar as críticas feita por Contreras (2002) sobre o ensino reflexivo no que diz respeito à responsabilidade social. O autor discute que a reflexão, por si só, pode não favorecer a superação da injustiça social e opressão, pois, os próprios docentes estão imersos em contradições e pressões sociais que não podem ser facilmente superadas. A própria estrutura escolar favorece a comparação e a competição entre os estudantes, considerando os modelos vigentes de avaliação e progressão do ensino. Sendo assim, ainda que os participantes da pesquisa tenham avançado na compreensão de suas responsabilidades sociais enquanto futuros docentes, isso não garante que consigam, em suas práticas, proporcionar oportunidades iguais para todos os estudantes.

\section{Relevância da pesquisa e reflexão sobre a prática: caminhos para emancipação docente}

A reflexão é vista pelos licenciandos, participantes da pesquisa, como possibilidade de transformar a prática, ao invés de reproduzir a lógica que impera nos sistemas de ensino tradicionais. É interessante observar a disposição dos licenciandos de examinarem suas práticas, indicando a disposição em melhorá-las com o tempo, conforme identificamos nos relatos abaixo:

"No decorrer da disciplina, passei por várias etapas que me permitiram repensar as minhas ações como futura professora. Os muitos desafios me 
impulsionaram ao desenvolvimento de uma postura mais autocrítica e reflexiva. [...] através dos questionamentos passamos a pensar mais sobre o que estamos fazendo" (Trecho da Narrativa da Aluna H);

“[...] a reflexão da prática a fim de poder melhorar o que não deu certo e nos aperfeiçoar cada vez mais de modo a despertarmos um olhar crítico-reflexivo sobre o sistema educacional, buscando alternativas para desenvolvermos habilidades e técnicas didáticas a fim de melhorar a relação professor-aluno e os demais problemas vivenciados em sala de aula." (Trecho da Narrativa da Aluna I).

Nos relatos acima podemos observar que a ideia de transformação da prática, a partir da reflexão, parece indicar uma preocupação mais evidente com o papel do professor nos processos ensino-aprendizagem. Não identificamos vinculação consciente do uso da reflexão para transformação social nos depoimentos e produções dos licenciandos.

O uso de expressões como "postura autocrítica e reflexiva" " "olhar crítico-reflexivo" não são explicitados a ponto de conseguirmos relacioná-los à preocupação com a justiça social. Sendo assim, estabelecemos uma relação entre o tipo de reflexão explicitado nos relatos dos licenciandos indicados acima, com a tradição de reflexão desenvolvimentista, proposta por Zeichner (1993), em que o professor reflete sobre questões do contexto mais interno da sala de aula, como interesses dos seus alunos, pensamento, padrões de desenvolvimento e aprimoramento da prática pedagógica.

Entretanto, os participantes demonstram preocupação em rever suas crenças e valores preexistentes e construídos ao longo do percurso formativo. Ainda que não vinculem esse movimento de análise nas discussões sobre a relevância da reflexão, essa preocupação se manifestou, em especial, nas discussões sobre temáticas relativas à multiculturalidade, diversidade étnica, questões de gênero, sexualidade, corpo, estética, consumismo e sustentabilidade. Dado o conteúdo e direcionamento político da reflexão realizada em diversos momentos, podemos identificar também indícios da tradição de reconstrução social proposta por Zeichner (1993), por trazer questões do contexto social na busca de transformação das práticas docentes.

Ao refletirem coletivamente sobre suas crenças, os licenciandos debatem sobre a relevância dos professores reconhecerem seus preconceitos e analisarem como suas ações podem ignorar ou até mesmo perpetuar situações discriminatórias. Trazemos um fragmento relatado por uma das alunas no sentido de exemplificar o exposto:

"Sobre o que você falou, quando se fala de homofobia, de identidade, de gênero é um assunto muito complexo. [...] eu entendo assim, a sua dificuldade de entender, isso é uma coisa construída historicamente. [...] É um assunto muito delicado. Quando você for professor vai ter em sua sala alunos que vão ter um comportamento, que vão fugir dos padrões, como é que você vai lidar? Você tem um aluno sendo discriminado pelo colega, lá sentado, você vai rir, você vai ignorar aquilo, porque se for você vai compactuar, eu entendo assim. Como você vai agir para combater esse tipo de preconceito. [...]. É uma coisa 
que às vezes é preciso você estar no lugar do outro para você refletir nas coisas que você faz." (Aluna $\mathrm{F}$, em relação à fala do Aluno C).

Segundo os participantes da pesquisa, as discussões ocorridas durante a disciplina, favoreceram a construção de um olhar mais crítico sobre a prática. Desta forma, a preocupação de análise do ensino não ficou restrita às questões internas da sala de aula, como de indisciplina, por exemplo. A pesquisa da prática por meio da observação orientou as ações em busca de superação dos limites observados, incorporando as questões sociais e a contextualização, favorecida pelo Enfoque CTS. Os trechos dos relatos abaixo exemplificam o que acabamos de mencionar:

\begin{abstract}
"[...] com o minicurso e regência, foi o momento em que, depois que eu observei tudo como estava se dando, eu fui colocar em prática aquilo que eu já tinha refletido. [...] as deficiências e os problemas que eu vi na observação que precisavam ser trabalhados foram usados na regência de maneira mais significativa no sentido de trabalhar temáticas na perspectiva CTS aproveitando os conhecimentos prévios dos estudantes levando em conta todo seus contextos social, econômico e também os outros fatos do seu dia-a-dia para dentro da sala de aula." (Aluna F);

"[...] a intenção é essa, de ser esse professor intelectual transformador, que sempre está em busca de pesquisar novas práticas para a sua sala, que se preocupa com as questões sociais e não fica só ali na teoria, na técnica." (Aluna E).
\end{abstract}

Os futuros professores estabelecem uma relação direta entre teoria e prática, evidenciando a importância da base teórica para uma prática que busque a transformação social. Zeichner (1993, 2002, 2008) ressalta a importância dessa compreensão ao explicitar que, apesar da relevância do conhecimento que emerge da prática dos professores, sem a vinculação deste com a teoria, ele pode se tornar vazio. Isto significa que, sem a mediação teórica, teremos dificuldades para avançar na análise crítica de nossas práticas.

Além disso, a mediação teórica é referência importante para a proposição de alternativas, como é o caso do Movimento CTS. Ainda segundo Zeichner (1993), a dicotomia teoria e prática não se justifica, tendo em vista que as teorias são produzidas a partir da prática, bem como as práticas refletem compromissos teóricos. Observamos que os licenciandos se aproximaram desta perspectiva, como podemos identificar nos relatos e trechos de narrativas a seguir:

\footnotetext{
"a gente tem que ter algum suporte, alguma base teórica. [...] essa parte aí, ficou bem clara para a gente, na docência, e principalmente no minicurso que a gente começou a trabalhar mais esses tópicos, essas estratégias, a gente conseguiu ver, teorizar e praticar, fazendo isso de forma consciente. Porque a gente quer gerar transformações, no sentido, não de controlar, dominar, mas de possibilitar transformações" (Aluno A);
}

"As discussões, seguidas de reflexões ocorridas na disciplina [...] nos deram subsídios teóricos para confrontarmos com nossas vivências e práticas educacionais no período de estágio supervisionado, seja na elaboração dos 
planos de aula da regência, minicurso e até mesmo os trabalhos desenvolvidos em sala" (Trecho da Narrativa da Aluna I).

Como se nota, as reflexões empreendidas ao longo da disciplina auxiliaram os licenciandos a perceber e criticar a redução do docente à aplicação de técnicas advindas da teoria. Segundo Contreras (2002) essa postura, característica de programas formativos embasados por uma perspectiva de racionalidade técnica, favorece a despolitização da educação, do conhecimento e do ensino.

A formação voltada para a racionalidade técnica é criticada por diversos autores que abordam a formação de professores (CONTRERAS, 2002; ZEICHNER, 1993, 2002, 2008; CARR; KEMMIS, 2004; GIROUX, 1997), por desconsiderar a influência sócio-histórica, o caráter político e a função social do ensino, bem como a relevância do papel dos professores como produtores de suas práticas, capazes de analisar as concepções que guiam suas ações e orientá-las em busca da transformação social de seus alunos. Em oposição à perspectiva técnica, os autores supracitados defendem uma formação voltada para a emancipação docente, pautada pela pesquisa e pela reflexão sobre a prática valorizadora do professor como intelectual.

A percepção de autonomia docente dos licenciandos vinculou-se à ideia de liberdade para assumir as decisões do ensino, criticando posturas de padronização, imposição e controle do trabalho docente, que reduzem os professores ao papel de técnicos, que reproduzem normas e práticas ditadas pela academia e pelos gestores e técnicos que comandam os sistemas de ensino. Podemos ver exemplos dessa percepção nos relatos abaixo apresentados:

"[...] algumas pessoas que desconhecem completamente a realidade do executar, do fazer, do estar dia a dia ali em sala de aula, muitas vezes são os responsáveis para elaborar o currículo, aquilo que vai ser colocado na sala de aula. E eu discordo porque eu acho que deveria ter uma forma de ao invés de vir de cima para baixo, vir de baixo para cima [...].” (Aluno C)

"Tá ali o professor tentando dar aula, mas ele está com argolas nos pés e nas mãos, como se ele fosse um joguete, está sendo totalmente controlado, a aula dele tem que seguir um padrão, ele tem que se encaixar no sistema, seguir as regras, tem que fazer aquilo que pedem para ele fazer, daquela forma. Ou seja, ele não tem autonomia na sua prática, no exercício da sua docência” (Aluno A)

\section{A autorreflexão sobre a prática docente e o reconhecimento de suas próprias limitações}

Durante as aulas da disciplina identificamos momentos em que os futuros professores expressaram uma prática autorrefletida, ou seja, aquela em que o professor busca examinar suas ações no intuito aprimorá-las. De acordo com Zeichner (1993), o processo de compreensão e melhoria do ensino começa justamente pela reflexão dos docentes e 
licenciandos sobre sua própria experiência. Apresentamos abaixo alguns trechos de relatos dos participantes da pesquisa que indicam momentos de autorreflexão:

\begin{abstract}
"As limitações pessoais foram observadas como exemplo, as tendências a determinada perspectiva em certos temas em detrimento de outros, algo que foi refletido para possível melhora posterior. Isso aqui foi uma reflexão pessoal minha, porque a perspectiva era CTSA, mas eu só ficava no $\mathrm{S}$ [social]. [...] não fazia o diálogo com a tecnologia e a ciência. E eu vi que isso é um problema grave mesmo meu. [...] é uma coisa que eu estou refletindo para trabalhar, melhorar" (Aluna F);
\end{abstract}

"Aí eu reconheço para o senhor que eu fiquei com medo de entrar naquele mundo que eu desconheço completamente. Aí eu não sei até onde seria... Na hora $\mathrm{H}$ eu disse: eu não vou entrar nesse mérito não" (Aluno C).

Ao analisarem suas práticas, os licenciandos refletiram sobre seus próprios limites em questões relacionadas ao planejamento e condução das aulas, com a insegurança de lidar com o desconhecido, de não conseguirem obter o retorno esperado dos alunos, a falta de domínio dos conteúdos, bem como as dificuldades em escolher e explorar adequadamente os recursos didáticos durante as aulas. De acordo com Carr e Kemmis (2004), ao assumir uma perspectiva crítica de ensino, o docente busca planejar cuidadosamente suas aulas, desenvolver suas ações de forma consciente, examinar sistematicamente as consequências de seus atos e refletir criticamente sobre os limites e possibilidades das estratégias de ensino adotadas. Segundo os referidos autores, o discurso privado, autorreflexivo possibilita o estabelecimento de comunidades críticas de investigadores. Dentro dessas comunidades, o contato com a experiência de outros professores favorece a comparação, a percepção de limites e a compreensão dos contextos em que outros professores agem. Da mesma forma, a experiência de expor a prática através do discurso, proporcionada em alguns momentos das aulas da disciplina, favoreceu condições para a análise e crítica das ações e, consequentemente, para uma prática reconstrutora.

Se considerarmos o contexto em que ocorreram os momentos de autorreflexão vividos pelos participantes da pesquisa, podemos estabelecer algumas relações destes com o entendimento apresentado por Carr e Kemmis (2004). Isto porque a crítica à própria ação, realizada pelos licenciandos, emergiu neste processo de discussão com o grupo e direcionouse não apenas ao reconhecimento dos limites das ações implementadas por eles durante as atividades de estágio, mas também houve a intenção deliberada de buscar, coletivamente, práticas alternativas e mais justas.

De acordo com Zeichner (1993) um dos aspectos que impede que o ensino reflexivo favoreça uma aprendizagem docente genuína é a orientação para que futuros professores reflitam individualmente sobre seus métodos de ensino, ignorando o contexto social e institucional escolar. 
Sendo assim, para além das questões relacionadas ao contexto mais interno da sala de aula (estratégias metodológicas, organização e dinâmica das aulas), os licenciandos trazem à discussão os desafios de estimular o desenvolvimento de uma formação crítica nos alunos, numa perspectiva que busque a função social do ensino:

[...] E às vezes a gente esquece justamente dessa questão de formar cidadãos, críticos, que a gente possa não transmitir, mas fazer com que eles possam de fato construir sua própria opinião, seu próprio conhecimento, aprender a tirar suas conclusões. [...] (Aluno C);

[...] a gente consegue desenvolver esses discursos mais críticos aqui. Mas, na sala de aula será que a gente está conseguindo transmitir isso para os alunos? [...] Aí chega lá na hora a gente tá tão fixo com essa ideia de estar passando o conteúdo que a gente esquece das outras partes, que precisa também levar outras questões para os alunos. É aquele velho clichê: Na prática é uma coisa, na teoria é outra. (Aluna E).

É interessante observar, nos depoimentos acima, que os licenciandos percebem as contradições entre os discursos que advogam em torno de uma formação cidadã e a efetiva prática docente, que muitas vezes privilegia a formação de natureza meramente conceitual, dentro de uma abordagem de transmissão de conhecimentos. A aluna E, por exemplo, entende essa contradição como uma separação entre teoria e prática, como se a teoria estivesse somente vinculada à universidade, que orienta os procedimentos e técnicas a serem aplicados em sala de aula, ou seja, na prática. Ao fazer uma reflexão com o grupo, que leva a uma análise das ações dos docentes em sala de aula, no que se refere à formação crítica dos alunos, a referida aluna acaba por destacar um limite da própria formação inicial.

Segundo Pimenta e Lima (2006), a crítica direcionada para a dicotomia entre teoria e prática é comum entre os licenciandos, sendo um indicativo de que os cursos de formação inicial não fundamentam "teoricamente a atuação do futuro profissional, nem toma(m) a prática como referência para a fundamentação teórica” (p. 6). Nesse sentido, concordamos com as referidas autoras, sobre a importância de o estágio promover vínculos entre o que se teoriza e se pratica, tanto na universidade como na escola, criando momentos para reflexão e análise das práticas institucionais à luz dos fundamentos teóricos das disciplinas e das experiências de seus profissionais. Identificamos pelos registros fixados no memorial descritivo que essas foram características marcantes na disciplina investigada, em que o professor buscou - a todo o momento- envolver os licenciandos em processos reflexivos sobre a prática embasados teoricamente.

\section{A autoformação contínua: em busca da superação dos limites da formação inicial}

De acordo com Zeichner (1993; 2002), a formação inicial deveria ajudar os futuros professores a desenvolverem a disposição e capacidade de estudar a maneira como ensinam, 
responsabilizando-se pelo seu próprio desenvolvimento profissional. Desta forma, podemos identificar que os licenciandos reconheceram que o processo formativo é contínuo e necessário, tanto pela superficialidade com que muitas questões são abordadas na licenciatura, como pelo caráter transitório dos conteúdos da área de Biologia. Como exemplo, apresentamos o relato do aluno $\mathrm{C}$, ocorrido durante um encontro presencial, que discutiu os sentidos de ensinar Biologia:

\begin{abstract}
"A gente percebe que [...] sai da graduação e a gente precisa estudar muito, buscar muito, porque é tudo muito superficial, é tudo assim eu vou dar o básico e você se aprofunde, [...] a gente acaba não aprofundando e o sentimento é de que: será que eu estou saindo da graduação e estou preparado? Em alguns casos eu vejo que sim, mas em outros eu sinto medo" (Aluno C).
\end{abstract}

Observamos que para o aluno $\mathrm{C}$, a insegurança gerada pela superficialidade percebida em relação à formação inicial leva à busca individual constante para complementar e atualizar seus conhecimentos. Porém, a análise de outros relatos do referido aluno demonstra que ele praticamente isenta a universidade da responsabilidade pelos limites da formação inicial, sugerindo que a culpa é dos próprios alunos da licenciatura, que não se dedicam suficientemente aos estudos.

Entendemos a importância do aluno se responsabilizar por seu processo formativo, mas a universidade tem papel fundamental na superação desses limites. Desta forma, concordamos com Trivelato (1993), quando afirma que os futuros professores não irão aprender tudo nos cursos de licenciatura, mas as Instituições de Ensino devem favorecer uma preparação adequada para que os docentes sejam capazes de buscar atualização continuamente.

Já para os alunos D e J, a formação é contínua porque aprendemos tanto com a pesquisa da prática, como com a teoria, e esse processo pode favorecer a emancipação docente, tal como podemos identificar nos relatos apresentados na sequência:

\footnotetext{
"Que tempo vai ser necessário para que estejamos devidamente preparados? [...] a educação, a Ciência está em verdadeira evolução. Então é por isso que nunca vamos nos sentir preparados, mas estar pronto para estar pesquisando e informando cada vez mais [...]." (Aluno D);

“[...] Entendo que o processo formativo é um exercício contínuo que sempre nos direciona a novas aprendizagens. [...]" (Trecho da Narrativa Aluna J).
}

\title{
O processo de fortalecimento da opção pela docência
}

Conforme os dados levantados sobre o perfil dos alunos, observamos que a maioria dos participantes da pesquisa não escolheu o curso de Licenciatura em Ciências Biológicas com intenção de seguir a carreira docente. Os alunos E e A, por exemplo, afirmam nas respostas de seus questionários que escolheram o curso porque era a opção mais acessível. Entretanto, esses alunos manifestaram nos encontros finais da disciplina, que a experiência vivida pôde resgatar 
o desejo de ser professor e incentivar a opção pela docência, o que podemos verificar nos relatos a seguir:

"[...] A regência no ensino médio, resgatou minha vontade de ser professor. [...] Então assim, consegui aplicar em sala de aula, ou me esforçar para aplicar, a teoria que a gente tem visto aqui, CTS, ver o resultado que produz isso, das discussões. [...] Me apaixonei de novo pela profissão! [...] Então, além das muitas contribuições, essa é a que eu destaco com maior valor. A realização de ter bem claro que é isso que eu quero" (Aluno A);

“[...] De fato eu gostei muito dessa experiência. [...] As contribuições [do estágio] para mim, no individual foi: despertar para a prática docente. [...] Porque no início do curso eu não me imaginava ainda dando aula" (Aluna E).

O estágio é um momento em que os licenciandos vivenciam a realidade da escola, percebendo assim as possibilidades, mas também os desafios envolvidos na profissão docente. Observamos nos relatos dos participantes que experiências decepcionantes nos estágios anteriores os levaram a pensar em desistir da carreira docente. Em contrapartida, eles identificaram na experiência positiva, vivida neste último estágio, o desejo de persistir, apesar dos desafios ainda existentes para a conclusão do curso e para o início efetivo da carreira docente.

De acordo com eles, o estágio é um momento de extrema importância para o professor, já que proporciona o contato com as instituições escolares, conhecer o contexto em que elas estão inseridas e o papel do professor para fazer a diferença na vida dos alunos. Assim, apesar de reconhecerem que existem inúmeros limites e dificuldades, a participação e o envolvimento dos alunos nas experiências desenvolvidas a partir de um Enfoque CTS, aliados à percepção da relevância do papel do professor contribuíram para que esses desafios não resultassem em desânimo e posturas de desistência quando eles refletiram sobre a opção de seguir a carreira docente.

Muitas vezes, quando o estágio é embasado pela racionalidade técnica, fundamentada no domínio de métodos e estratégias para sua aplicação em sala de aula, pode favorecer uma sensação de desânimo e decepção com a prática docente. Isso porque a realidade da escola é complexa e imprevisível e, portanto, o insucesso na aplicação de um método, ou no enfrentamento das condições atuais das escolas públicas, pode decepcionar o futuro professor e levá-lo ao abandono da carreira docente.

Em contrapartida, acreditamos que a racionalidade crítica oferece oportunidades de repensar o potencial de transformação da educação e o papel do professor nesse sentido, ao reconhecer que muitos dos desafios vivenciados pelos docentes na escola têm origens no contexto social.

Destacamos, neste sentido, a diversificação das estratégias desenvolvidas para o estágio, na disciplina investigada, que não se limitou às tradicionais observações e coparticipação da regência na escola. Dessa forma, na experiência analisada, houve ISSN 2526-2882 
possibilidades para a construção e replanejamento coletivo de propostas, reflexões sobre a prática embasadas teoricamente, além da experiência de extensão em que os futuros professores desenvolveram e aplicaram, em grupo, um minicurso.

Zeichner (1993) critica os estágios que se limitam exclusivamente ao domínio de sala de aula, em que o licenciando trabalha de forma isolada, apenas em uma turma e com um professor regente. O referido autor aponta ainda que, essa postura favorece a ideia de que o ensino é uma atividade solitária, reforça o papel do docente como técnico e a imitação passiva do professor regente. Pedretti e colaboradores (2006) também criticam os estágios que desvinculam a teoria da prática e sugerem que os futuros professores em formação devam ser incentivados a desenvolver propostas pautadas pelo Enfoque CTS.

Apoiados nessas críticas de Zeichner (1993) e de Pedretti et al. (2006), destacamos a importância do minicurso no estágio vivenciado pelos participantes. Isso porque, na regência, os licenciandos estavam submetidos ao currículo tradicional da escola e às orientações mais explícitas do professor regente. Sendo assim, nem todos conseguiram desenvolver suas aulas na regência a partir de um Enfoque CTS. Já nos minicursos, houve liberdade e flexibilidade para que os licenciandos pudessem elaborar seus planejamentos, de forma coletiva, ampliando a possibilidade de estimular a criatividade e responsabilidade dos futuros profissionais envolvidos no processo.

Por fim, ressaltamos que os licenciandos consideraram que o suporte teórico, bem como as discussões ocorridas durante a disciplina, foram fundamentais para apoiar o desenvolvimento da atividade docente, o que evidencia um reconhecimento da importância de aliar teoria e prática no ensino.

\section{Considerações Finais}

Nossa pesquisa investigou as reflexões sobre a docência realizadas pelos futuros professores ao planejarem e desenvolverem suas propostas de estágio supervisionado por meio do Enfoque CTS, com alunos do ensino médio.

A partir dos resultados apontados, ressaltamos o entendimento dos participantes de que a docência é uma prática coletiva, dotada de caráter político, o que leva o professor a considerar sua responsabilidade social, de fazer a diferença na vida dos alunos. Sendo assim, os licenciandos valorizaram a importância de pesquisar e refletir sobre sua prática, identificando seus próprios limites e procurando aprimorar suas práticas e sua própria formação. A experiência com Enfoque CTS, desenvolvida no estágio, resgatou, em alguns dos participantes, o desejo de assumir a função docente.

Tendo em vista a síntese das reflexões desencadeadas nos estudantes, destacamos que as contribuições alcançadas pela experiência vivida durante a disciplina, sob análise na pesquisa, aproximaram os futuros professores de uma visão crítica, em relação ao ensino e à 
docência, evidenciadas pelas tentativas de romper com os limites do ensino tradicional e de superar a ideia de docência como prática isolada, autoritária, desvinculada da realidade social e reprodutora de propostas elaboradas por terceiros.

Os aspectos observados nesta investigação não são resultado apenas do trabalho desenvolvido na disciplina analisada. O percurso formativo dos participantes, as suas histórias de vida, os contextos vivenciados, tanto na formação acadêmica, quanto nos diferentes espaços não formais, como nos coletivos de transformação social e política (movimentos sociais, instituições religiosas e sindicatos), foram de fundamental importância para que pudessem emergir durante o processo vivido no estágio, os contributos que destacamos para a formação dos futuros professores participantes da pesquisa. Dessa forma, ressaltamos ser importante levar em conta a trajetória formativa dos licenciandos, buscando aproveitar os elementos que eles trouxeram para o desenvolvimento do grupo.

Considerando as contribuições identificadas no trabalho, somadas a outras experiências descritas na literatura, defendemos a inserção dos pressupostos do Movimento CTS e da reflexão crítica, teoricamente embasada, na formação inicial e continuada de professores. Acreditamos que seja essa uma das alternativas possíveis para repensarmos a formação docente e direcioná-la para a problematização das condições sociais, levando em conta o desenvolvimento científico e tecnológico e os diversos aspectos sociais, históricos, políticos, éticos e morais que os envolvem. Entendemos que os resultados destacados precisam ser adaptados e pensados dentro do contexto específico de cada instituição, mas podem ser objeto de reflexões que envolvam outras situações e espaços formativos.

\section{Referências}

AZEVEDO, R. O. M.; GHEDIN, E.; FORSBERG, M. C. S.; GONZAGA, A. M. O enfoque CTS na formação de professores de Ciências e a abordagem de questões Sociocientíficas. In: Encontro Nacional de Pesquisa em Ensino de Ciências, 9., 2013. Águas de Lindóia. Atas... São Paulo: ABRAPEC, 2013. Disponível em: http://www.nutes.ufrj.br/abrapec/ixenpec/atas/resumos/Ro325-1.pdf . Acesso em o4 dez. 2019.

BARDIN, L. Análise de conteúdo. Lisboa: Edição 70, 2011.

BAZZO, W. A.; VON LINSINGER, I,; PEREIRA, L. T. V. (Eds.) Introdução aos estudos CTS (Ciência, Tecnologia e Sociedade). Madrid: Organização dos Estados Iberoamericanos para a Educação, a Ciência e a Cultura (OIE), 2003. Disponível em: https://www.oei.es/historico/salactsi/introducaoestudoscts.php>. Acesso em 04 dez. 2019.

BINATTO, P. F; Enfoque Ciência, Tecnologia e Sociedade (CTS) na Formação Reflexiva de Futuros Professores de Biologia: Possibilidades, Desafios e ISSN 2526-2882 
Contribuições. 2015. 151 f. Dissertação (Mestrado em Educação Científica e Formação de Professores). Universidade Estadual do Sudoeste da Bahia, Jequié, 2015. Disponível em: $<$ http://www2.uesb.br/ppg/ppgecfp/wpcontent/uploads/2017/o3/zPriscila-F-Binatto.3.pdf>. Acesso em 04 dez. 2019.

BINATTO, P. F.; CHAPANI, D. T.; DUARTE, A. C. S. Formação reflexiva de professores de ciências e enfoque ciência, tecnologia e sociedade: possíveis aproximações. Alexandria: Revista de Educação em Ciência e Tecnologia, v. 8, n. $\quad 1, \quad$ p. 131-152, 2015. Disponível em: <https://periodicos.ufsc.br/index.php/alexandria/article/view/19825153.2015v8n1p131/29303>. Acesso em o4 dez. 2019.

BOGDAN, R. C.; BIKLEN, S. K. Investigação qualitativa em educação: uma abordagem à teoria e aos métodos. Porto: Porto Editora,1997.

CARNIO, M. P.; CARVALHO, W. L. P. O tratamento de Questões Sociocientíficas na formação de professores de ciências: possibilidades e desafios nas vozes dos licenciandos. In: Encontro Nacional de Pesquisa em Ensino de Ciências, 9., 2013. Águas de Lindóia. Atas... São Paulo: ABRAPEC, 2013. Disponível em: <http://www.nutes.ufrj.br/abrapec/ixenpec/atas/resumos/R1689-2.pdf>. Acesso em 04 dez. 2019.

CARR, W.; KEMMIS, S. Becoming Critical: Education, Knowledge and Action Research. Taylor \& Francis e-Library, 2004.

CASSIANI, S.; LINSINGEN, I. V. Formação inicial de professores de Ciências: perspectiva discursiva na educação CTS. Revista Educar, Curitiba, s/v, n.34, p. 127-147, 2009. Disponível em: <http://www.scielo.br/pdf/er/n34/o8.pdf>. Acesso em 04 dez. 2019.

CHAPANI, D. T. Políticas públicas e história de formação de professores de Ciências: uma análise a partir da teoria social de Habermas. 2010. $421 \mathrm{f}$. Tese (Doutorado em Educação para Ciência) - Faculdade de Ciências, Universidade Estadual Paulista Júlio de Mesquita Filho, Bauru, 2010. Disponível em: <http://www2.fc.unesp.br/BibliotecaVirtual/DetalhaDocumentoAction.do?idDocu mento=294>. Acesso em o4 dez. 2019.

CONTRERAS, J. A autonomia de professores. São Paulo: Cortez, 2002.

DASS, P. Using a Science/Technology/Society Approach to Prepare Reform-Oriented Science Teachers: The Case of a Secondary Science Methods Course. Issues in Teacher Education, Califórnia, v. 14, n. 1, p. 95-108, 2005. Disponível em: < https://files.eric.ed.gov/fulltext/EJ796421.pdf >. Acesso em 04 dez. 2019.

FERNANDES, R. F.; STRIEDER, R. B. Questionamentos e Opiniões de professores de Ciências da Natureza sobre Educação CTS. Indagatio Didactica, v. 8, n. 1, 2016. Disponível 
em: <http://revistas.ua.pt/index.php/ID/article/view/3883>. Acesso em $04 \mathrm{dez}$. 2019.

FERRAZ, L. N. D. C. V. Metodologia do ensino das Ciências: concepção e avaliação de uma acção de formação contínua para professores numa perspectiva CTS. 2009. 662f. Tese de Doutorado. Universidade do Minho: Portugal, 2009. Disponível em: $<$ http://repositorium.sdum.uminho.pt/handle/1822/9859>. Acesso em $04 \mathrm{dez}$. 2019.

BISPO FILHO, D. D. O. .; MACIEL, M. D.; SEPINI, R. P.; ALONSO, Á. V. Alfabetização científica sob o enfoque da Ciência, Tecnologia e Sociedade: implicações para a formação inicial e continuada de professores. Revista Electrónica de Enseñanza de las Ciencias, v. 12, n. 2, p. 313-333, 2013. Disponível em: < http://reec.uvigo.es/volumenes/volumen12/REEC_12_2_5_ex649.pdf >. Acesso em o4 dez. 2019.

GHEDIN, E. Professor reflexivo: da alienação da técnica à autonomia da crítica. In: PIMENTA, S. G.; GHEDIN, E. (Orgs.). Professor reflexivo no Brasil: gênese e crítica de um conceito. 3. ed. São Paulo: Cortez, 2005, p. 129-150.

GIROUX, H. Os professores como intelectuais: rumo a uma pedagogia crítica da sociedade. Porto Alegre: Artmed, 1997.

HUNSCHE, S. Professor “Fazedor" de Currículos: Desafios no Estágio Curricular Supervisionado no Ensino de Física. 2010. 144 f. Dissertação (Mestrado em Educação). Universidade Federal de Santa Maria, Santa Maria, 2010. Disponível em: <https://repositorio.ufsm.br/handle/1/6909>. Acesso em o4 dez. 2019.

JORGENSEN, D.L. Participant Observation: a methodology for human studies. London: Sage Publications, 1989.

MARTÍNEZ, L. P. F. A abordagem de questões sociocientíficas na formação continuada de professores de Ciências: contribuições e dificuldades. 2010. 351f. Tese (Doutorado em Educação para Ciência). Faculdade de Ciências, Universidade Estadual Paulista, Bauru, 2010. Disponível em: <https://repositorio.unesp.br/handle/11449/102011>. Acesso em 04 dez. 2019.

MARTÍNEZ, L. P. F.; CARVALHO, W. L. P. Contribuições e dificuldades da abordagem de questões sociocientíficas na prática de professores de ciências. Educação e Pesquisa, São Paulo, v. 38, n. 03, 2012. Disponível em:<http://www.scielo.br/pdf/ep/2012nahead/aop450.pdf $>$. Acesso em $04 \mathrm{dez}$. 2019.

MARTÍNEZ, L. P. F.; LOZANO, D. L. P. La emergencia de las cuestiones sociocientíficas en el enfoque CTSA. Góndola. v. 8, n. 01, p. 22-35, 2013. Disponível em: 
<https://revistas.udistrital.edu.co/index.php/GDLA/article/view/5021>. Acesso em O4 dez. 2019.

MION, R.; ALVES, J.; CARVALHO, W. Implicações da relação entre Ciência, Tecnologia, Sociedade e Ambiente: subsídios para a formação de professores de Física. Experiências em Ensino de Ciências, v. 4, n. 2, p. 47-59, 2009. Disponível em: http://www.nutes.ufrj.br/abrapec/vienpec/CR2/p914.pdf>. Acesso em 04 dez. 2019.

PEDRETTI, E.; BENCZE, L.; HEWITT, J.; ROMKEY, L; JIVRAJ, A. Promoting issues-based STSE perspectives in science teacher education: Problems of identity and ideology. Science \& Education. v.17, n. 8-9,p. 941-960, 2006.

PINHEIRO, N. A. M.; MATOS, E. A. S. A. e BAZZO, W. A. Refletindo acerca da ciência, tecnologia e sociedade: enfocando o ensino médio. Revista Iberoamericana de Educación, n. 44, maio/agosto 2007. Disponível em: <https://rieoei.org/historico/documentos/rie44ao8.htm>. Acesso em 04 dez. 2019.

PIMENTA, S. G.; LIMA M. S. L. Estágio e docência: diferentes concepções. Revista Poíesis. Volume 3, Números 3 e 4, pag.5-24, 2005/2006.Disponível em: $<$ http://www.revistas.ufg.br/index.php/poiesis/article/view/10542/7012>. Acesso em 04 dez. 2019.

ROZA, C. F. Enfoque CTS no ensino de física: um estudo com estagiários da licenciatura em física. 111 f. Dissertação (Mestrado em Educação). Setor de Educação, Universidade Federal do Paraná, Curitiba, 2011. Disponível em: < https://acervodigital.ufpr.br/handle/1884/36421>. Acesso em 04 dez. 2019.

SANTOS, W. L. P. Significados da educação científica com enfoque CTS. In: SANTOS, W.L.P.; AULER, D. (orgs.) CTS e educação científica: desafios, tendências e resultados de pesquisas. Brasília: Editora Universidade de Brasília. 2011.

Educação CTS e cidadania confluências e diferenças. Amazônia Revista de Educação em Ciências e Matemáticas. v.9, n. 17, p. 49-62, 2012. Disponível em:

<https://periodicos.ufpa.br/index.php/revistaamazonia/article/view/1647/2077> Acesso em 04 dez. 2019.

SOARES, M. N. O estágio curricular supervisionado na licenciatura em Ciências biológicas e a busca pela experiência formativa: aproximações e desafios. 2012. 262 f. Tese (Doutorado em Educação para Ciência). Faculdade de Ciências, Universidade Estadual Paulista Júlio de Mesquita Filho, Bauru, 2012. Disponível em:http://www2.fc.unesp.br/BibliotecaVirtual/DetalhaDocumentoAction.do?idDoc umento=543. Acesso em o4 dez. 2019. 
STRIEDER, R. Abordagem CTS e Ensino Médio: Espaços de articulação. 2008. 236 f. Dissertação (Mestrado em Ensino de Ciências). Faculdade de Educação, Universidade de São Paulo, São Paulo, 2008. Disponível em: <https://www.teses.usp.br/teses/disponiveis/81/81131/tde-01072013-135158/ptbr.php> Acesso em 04 dez. 2019.

Abordagens CTS na educação científica no Brasil: sentidos e perspectivas. 2012. 282 f. Tese (Doutorado em Ciências). Faculdade de Educação, Universidade de São Paulo, São Paulo, 2012. Disponível em:< https://www.teses.usp.br/teses/disponiveis/81/81131/tde-13062012-112417/ptbr.php>. Acesso em 04 dez. 2019.

STRIEDER, R. B.; KAWAMURA, M. R. Panorama das pesquisas pautadas por abordagens CTS. In: Encontro nacional de pesquisa em educação em ciências, 7, 2009, Florianópolis. Anais... Belo Horizonte: ABRAPEC, 2009. Disponível em: <http://www.posgrad.fae.ufmg.br/posgrad/viienpec/pdfs/463.pdf>. Acesso em o4 dez. 2019.

TEIXEIRA, P. M. M. Ensino de biologia e cidadania: o técnico e o político na formação docente. 2000. 315 f. Dissertação (Mestrado em Educação para Ciência) - Faculdade de Ciências, Universidade Estadual Paulista, Bauru, 200o. Disponível em: <https://repositorio.unesp.br/bitstream/handle/11449/90979/teixeira_pmm_me_ bauru.pdf? sequence=1>. Acesso em 04 dez. 2019.

. A Educação Científica sob a perspectiva da Pedagogia HistóricoCrítica e do movimento CTS no ensino de Ciências. Ciência \& Educação, v. 9, n. 2, p. 177-190, 2003. Disponível em: < http://www.scielo.br/pdf/ciedu/v9n2/o3.pdf>. Acesso em 04 dez. 2019.

TRIVELATO, S. L. F. A formação de professores e o enfoque CTS. Pensamiento Educativo, Santiago de Chile, v. 24, p. 201-234, 1999. Disponível em: <https://pensamientoeducativo.uc.cl/files/journals/2/articles/149/public/149-3741-PB.pdf>. Acesso em 04 dez. 2019.

UESB. Projeto pedagógico do curso de ciências biológicas. Jequié: UESB, 2011. Acesso em 04 dez. 2019. Disponível em: < http://www2.uesb.br/proreitorias/prograd/wpcontent/uploads/doc_cursos/biologia-bac-jq-mat_projeto-pedagogico.pdf $>$. Acesso em 04 dez. 2019.

VACCAREZZA, L. Ciencia, Tecnología y Sociedad: el estado de la cuestión em América Latina. Revista Iberoamericana en Educación, n. 18, p. 13-40. 1998. Disponível em: <https://rieoei.org/RIE/article/view/1090>. Acesso em 04 dez. 2019.

VERASZTO, E. V. Tecnologia e sociedade: relações de causalidade entre concepções e atitudes de graduandos do Estado de São Paulo. 2009. Tese (Doutorado em 
Educação) - Faculdade de Educação, Universidade Estadual de Campinas, 2009. Disponível em: <http://repositorio.unicamp.br/jspui/handle/REPOSIP/251718>. Acesso em 04 dez. 2019.

VON LINSINGER, I. Perspectiva educacional CTS: aspectos de um campo em consolidação na América Latina. Ciência \& Ensino (UNICAMP), v. 1, p. 01-16, 2007. Disponível em: $<$ http://200.133.218.118:3535/ojs/index.php/cienciaeensino/article/view/15o/108 $>$. Acesso em 04 dez. 2019.

ZEICHner, K. M. A Formação Reflexiva de Professores: Ideias e Práticas. Lisboa: Educa, 1993 .

- Formando professores reflexivos para uma educação centrada no aprendiz: possibilidades e contradições. In: ESTEBAN, M. T.; ZACCUR, E. (org.). Professora Pesquisadora: uma práxis em construção. 2. ed. Rio de Janeiro: DP\&A, . p. $25-52,2002$.

. Uma análise crítica sobre a "reflexão" como conceito estruturante na formação docente. Educação \& Sociedade, v. 29, n. 103, p. 535-554, 2008. Disponível em: <http://www.scielo.br/pdf/es/v29n103/12.pdf>. Acesso em $04 \mathrm{dez}$. 2019.

\section{Biografia Resumida}

Priscila Franco Binatto: Professora do Intistuto Federal do Norte de Minas Gerais (IFNMG), Campus Arinos. Mestre em Educação Científica e Formação de Professores pela UESB (2015). Especialista em Ensino de Ciências por Investigação pela UFMG (2012) e graduada em Ciências Biológicas pelo Centro Universitário do Leste de Minas Gerais (2003). Participa do Grupo de Estudos e Pesquisas: Movimento CTS e Educação Científica (GP-CTS). Tem experiência em ensino de Ciências e Biologia com enfoque CTS, formação de professores e ensino por investigação.

Lattes: http://lattes.cnpq.br/4154036081939494

Contato:priscila.binatto@ifnmg.edu.br

Ana Cristina Duarte Santos: Professora Pleno do Departamento de Ciência Biológicas da Universidade Estadual do Sudoeste da ISSIV $23 \angle 6-2882$ 
Bahia (UESB), Campus Jequié, da área Educação e Prática de Ensino. Docente, pesquisadora do Programa de Pós-Graduação em Educação Científica e Formação de Professores (DCB/UESB), e do Programa de Pós-Graduação em Enfermagem e Saúde (DS/UESB). Pós-Doutora em Didactica de las Ciencias Experiementales, na Universidad Nacional del Litoral (2003). Doutora em Educação pela Universidade Federal da Bahia (2004). Mestre em Educação pela Universidade Federal da Bahia (1999). Graduada em Ciências com Habilitação Em Biologia pela Universidade Estadual do Sudoeste da Bahia (1990). Tem experiência na área de Educação, com ênfase em Formação de Professores, atuando principalmente nos temas: ensino de Ciências e Biologia; educação inclusiva; aprendizagem; educação; diversidade.

Lattes: http://lattes.cnpq.br/3604631474755045

Contato: tinaduarte2@gmail.com

Paulo Marcelo Marini Teixeira: Professor Titular do Departamento de Ciência Biológicas da Universidade Estadual do Sudoeste da Bahia (UESB), Campus Jequié/BA, da área de Educação e Prática de Ensino. É também docente, pesquisador do Programa de Pós-Graduação em Educação Científica e Formação de Professores (DCB/UESB). Pós-Doutorado pela Faculdade de Educação da Unicamp (2015-2016). Doutorado em Educação pela Faculdade de Educação da Unicamp (2008). Mestre em Educação para a Ciência pela Universidade Estadual Paulista (UNESP/Bauru, 2000). Graduado em Ciências com Habilitação em Biologia pela Universidade do Sagrado Coração (USC, 1990), Licenciado em Matemática pela Universidade Estadual Paulista Júlio de Mesquita Filho (UNESP, 1994). É líder do Grupo de Estudos e Pesquisas: Movimento CTS e Educação Científica (GP-CTS), vinculado ao referido programa de pósgraduação; é editor da Revista de Iniciação à Docência (RIDUESB). Tem experiência na área de Educação em Ciências, com ênfase na Formação de Professores, atuando principalmente nas seguintes linhas de pesquisa e temáticas de estudo: Educação, Ensino de Biologia, Educação Científica, Movimento CTS, 
Pesquisa e Formação de Professores, Produção Acadêmica em Ensino de Ciências/Biologia - Estado da Arte.

Lattes: http://lattes.cnpq.br/3604631474755045

Contato: pmarcelo@uesb.edu.br 